Jurnal Laut Khatulistiwa, Vol. 4 No. 2 (July, 2021), Hal. 6-11.

ISSN : 2614-6142 (Printed), 2614-8005 (Online)

http://jurnal.untan.ac.id/index.php/lk

JURNAL LAUT

KHATULISTIWA

\title{
Komposisi dan Distribusi Gastropoda di Desa Bakau Besar Laut Kecamatan Sungai Pinyuh, Kabupaten Mempawah
}

\section{Composition and Distribution Pattern Of Gastropods on The Bakau Besar Laut Village, The District Of Sungai Pinyuh, Mempawah Regency}

\author{
Gabriella Maura $^{1 *}$, Anthoni B. Aritonang ${ }^{2}$, Shifa Helena ${ }^{3}$ \\ ${ }^{1}$ Program Studi Ilmu Kelautan, FMIPA Universitas Tanjungpura, Pontianak, Indonesia \\ ${ }^{2}$ Program Studi Kimia, FMIPA Universitas Tanjungpura, Pontianak, Indonesia \\ ${ }^{1}$ Laboratorium Ilmu Kelautan, FMIPA Universitas Tanjungpura, Pontianak, Indonesia \\ *Email : gabriellamaura06@gmail.com
}

Received : 10 Mei 2021; Accepted: 19 Juli 2021

Published: 31 July (C) Author(s) 2021. This article is open access

\begin{abstract}
Gastropod is one of the biota that generally used as indicator of aquatic environment. Location of Bakau Besar Laut has 3 kind of settlement, ecotourism, and shrimp farm. Presence of gastropods are important since their existence is an indication of the water quality. The purpose on this research is to find the scheme of composition and distribution of gastropods at Bakau Besar Village, The region of Sungai Pinyuh, Mempawah Regency. On each stasions was made 1 line transect with a distance 23 m and on each transects consist of 3 plot meansuring $1 \times 1 \mathrm{~m}$ with a distance between plots $10 \mathrm{~m}$. Environmental parameters meansured convering temperature, $p H$ (power of hydrogen), salinity, and type of substrate. The results from research was found composition type of gastropods in Bakau Besar Laut Village was found to be species of Cerithidea cingulata, C. obtusa, C. weyersi, Littoria scabra, L. undolata, Nerita violacea, Strombus mutabilis, and distribution patterns of gastropods in each station are clumped.
\end{abstract}

Keywords : Gastropods, Composition of Gastropods, Distribution of Gastropods, Bakau Besar Laut Village

\begin{abstract}
Abstrak
Gastropoda adalah salah satu biota yang sering digunakan sebagai indikator lingkungan suatu perairan. Lokasi Bakau Besar Laut memiliki 3 rona lingkungan yaitu pemukiman, ekowisata, dan tambak udang. Sebagai dasar dari penelitian ini membutuhkan informasi terkait kualitas lingkungan dengan gastropoda sebagai indikator. Penelitian ini bertujuan untuk mengetahui komposisi dan distribusi gastropoda di Desa Bakau Besar Laut Kecamatan Sungai Pinyuh, Kabupaten Mempawah. Masing-masing stasiun dibuat 1 garis transek sepanjang $23 \mathrm{~m}$. Setiap transekterdiri dari 3 plot berukuran $1 \times 1 \mathrm{~m}$ dengan jarak antar plot $10 \mathrm{~m}$. parameter lingkungan yang diukur meliputi suhu, $\mathrm{pH}$, salinitas, dan jenis substrat. Berdasarkan hasil penelitian ditemukan komposisi dari jenis-jenis gastropoda yaitu Cerithidea cingulata, C. obtusa, C. weyersi, Littoria scabra, L. undolata, Nerita violacea, Strombus mutabilis dengan pola distribusi mengelompok.
\end{abstract}

Kata kunci : Gastropoda, Komposisi Gastropoda, Distribusi Gastropoda, Desa Bakau Besar Laut.

\section{Pendahuluan}

Desa Bakau Besar Laut merupakan wilayah pesisir yang terletak di Kecamatan Sungai Pinyuh Kabupaten Mempawah Provinsi Kalimantan Barat (BPS Kabupaten Mempawah, 2018). Wilayah pesisir adalah wilayah peralihan air tawar dan asin yang ditempati beragam ekosistem salah satunya adalah ekosistem mangrove. Secara ekologi ekosistem mangrove berperan sebagai nutrient pool yang sangat penting bagi biota yang hidup di perairan tersebut (Ardiyansyah, 2018).

Gastropoda merupakan salah satu biota yang hidup di lingkungan mangrove. 
Gastropoda menjadikan hutan mangrove sebagai habitat hidupnya. Secara umum gastropoda memiliki peran penting sebagai rantai makanan komponen biotik dan dekomposisi serasah daun (Hamida, 2016). Gastropoda sering digunakan sebagai indikator lingkungan perairan karena sangat peka terhadap perubahan kualitas air tempat hidupnya, pergerakan yang lambat, dan pola makan detritus (Ahmad, 2018).

Ekosistem mangrove di pesisir Desa Bakau Besar Laut merupakan daerah konservasi, namun adanya kegiatan manusia pada kawasan ini diduga akan memberikan dampak negatif terhadap habitat gastropoda.

Kegiatan pembangunan di wilayah mangrove diantaranya adalah ekowisata, tambak dan pemukiman. Kegiatan tersebut mengakibatkan semakin sempitnya ekosistem mangrove dan berdampak pada pola distribusi dan komposisi gastropoda di wilayah tersebut.

\section{Metodologi Penelitian}

\subsection{Waktu dan Tempat Penelitian}

Pengambilan data penelitian ini dilaksanakan pada bulan Juli 2019 di Kawasan Hutan Mangrove Desa Bakau Besar Laut Kecamatan Sungai Pinyuh Kabupaten
Mempawah. Analisis substrat dilakukan di Laboratorium Mekanika Tanah Fakultas Teknik, Universitas Tanjungpura, Pontianak. Wilayah penelitian dibagi menjadi 3 stasiun yang diperoleh menggunakan metode purposive sampling dapat dilihat pada Gambar 1.

Berdasarkan rona lingkungan yang digunakan, Stasiun I berada di dekat pemukiman warga, Stasiun II berada di kawasan ekowisata dan Stasiun III berada di kawasan mangrove yang dekat dengan tambak udang.

\subsection{Metode Penelitian}

Data gastropoda diambil menggunakan metode line transek pada setiap stasiun. Transek dibuat pada setiap stasiun dengan menarik garis atau line sepanjang $23 \mathrm{~m}$ sejajar garis pantai. Setiap transek terdiri dari 3 plot, setiap plot berukuran $1 \times 1 \mathrm{~m}$ dengan jarak antar plot 10 m (lihat Gambar 2) (Andriani et al., 2018). Data gastropoda yang diambil meliputi jenis gastropoda, pola sebaran, dan substrat tempat hidup gastropoda.

Pengambilan sampel dilakukan pada saat kondisi surut dan tidak hujan. Pengambilan sampel gastropoda dilakukan secara langsung dengan cara memungut menggunakan tangan

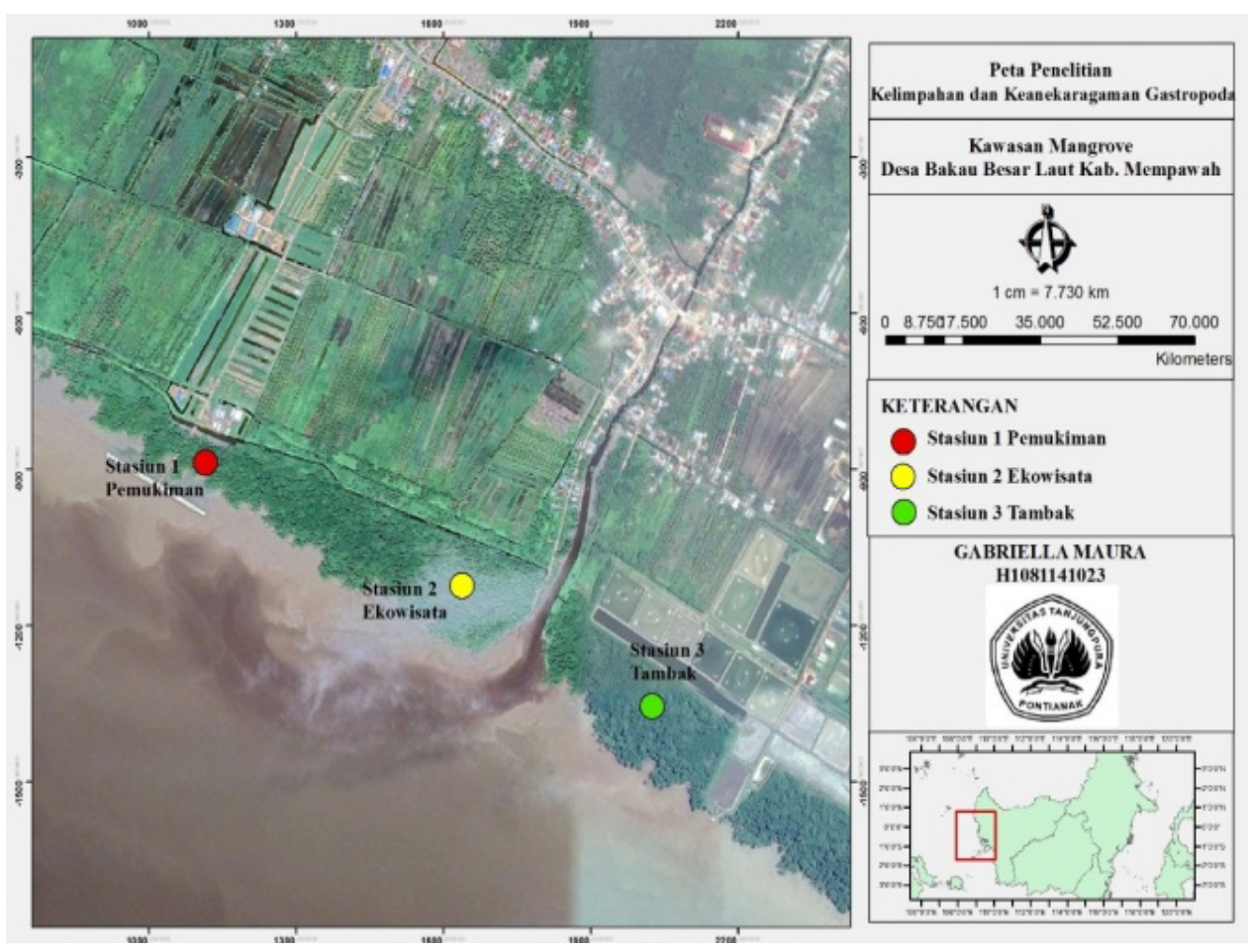

Gambar 1. Peta Lokasi Penelitian 
Jurnal Laut Khatulistiwa, Vol. 4. No. 2 (July, 2021), Hal. 6-11.

dan sampel yang berada di atas substrat maupun yang menempel pada akar mangrove yang berada dalam plot diambil seluruhnya.

Gastropoda yang telah didapat kemudian di amati dan dimasukkan ke dalam kantong plastik yang telah diberi kertas label dan kemudian diawetkan menggunakan alkohol $70 \%$. Sampel gastropoda dibawa untuk diamati di Laboratorium Ilmu Kelautan, Fakultas Matematika dan Ilmu Pengetahuan Alam, Universitas Tanjungpura, kemudian sampel diidentifikasi menggunakan buku identifikasi Niem and Carpenter.

Parameter fisika dan kimia yang diukur meliputi Suhu, pH, dan Salinitas. Hasil pengukuran parameter tersebut dijadikan sebagai data pendukung dalam penelitian ini.

\subsection{Analisis Data}

Pola distribusi gastropoda dihitung dengan menggunakan Indeks Morisita (Id) dengan persamaan sebagai berikut (Krebs, 1989):

$$
\mathrm{I}_{\mathrm{d}}=\frac{\mathrm{N} \sum \mathrm{x}^{2-} \sum \mathrm{x}}{\left(\sum \mathrm{x}\right)^{2-} \sum \mathrm{x}}
$$

Keterangan :

Id : Indeks Morisita

$\mathrm{N} \quad$ : Jumlah seluruh plot pengambilan sampel

$\sum \mathrm{x}^{2} \quad$ : Total dari kuadrat jumlah individu seluruh plot

$\sum \mathrm{x} \quad$ : Total dari jumlah individu seluruh plot
Persamaan berikut dihitung terkait yang signifikan bagi Indeks Morisita (Krebs, 1989). Indeks Keseragaman :

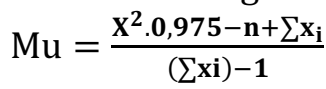

Indeks Pengelompokan :

Mc $=\frac{X^{2} .0,025-n+\sum x_{i}}{\left(\sum X i-1\right)}$

Keterangan:

$\mathrm{Mu} \quad$ : Indeks Morisita untuk pola sebaran seragam

Mc : Indeks Morisita untuk pola sebaran Mengelompok

$\mathrm{X}^{2} \cdot 0,975$ : Nilai chi-square tabel dengan derajat bebas $n-1$

$\mathrm{X}^{2} .0,025$ : Nilai chi-square tabel dengan derajat bebas $\mathrm{n}-1$

$\mathrm{x}_{\mathrm{i}} \quad$ : Jumlah individu dalam plot

n : Jumlah seluruh plot pengambilan sampel

Standarisasi Indeks Morisita dihitung dengan salah satu persamaan dibawah (Krebs, 1989).

$$
\begin{aligned}
& \text { Ip }=0,5+0,5\left(\frac{\text { Id-Mc }}{n-M c}\right) \\
& I p=0,5\left(\frac{I d-1}{M c-1}\right) \\
& I p=0,5\left(\frac{I d-1}{M c-1}\right) \\
& I p=-0,5+0,5\left(\frac{I d-M u}{M u}\right)
\end{aligned}
$$

Rumus Ip yang didapatkan kemudian dijelaskan sebagai berikut:

Ip $<0 \quad$ : Penyebaran bersifat merata

$\mathrm{I} p=0 \quad$ : Penyebaran bersifat acak

\section{Garis Pantai}

\section{St.1}
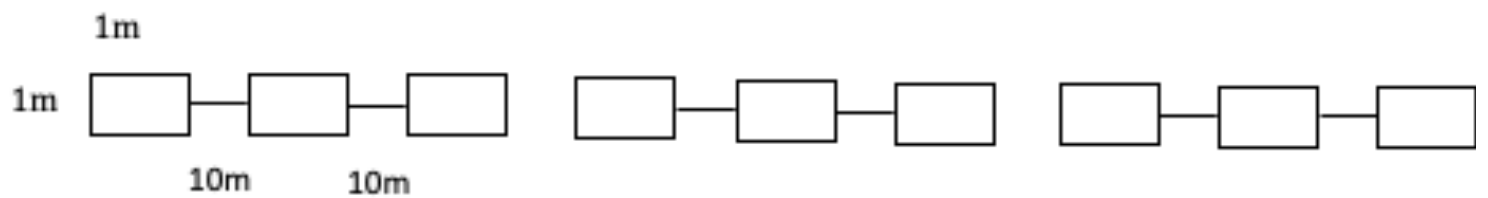

Gambar 2. Pembuatan transek dan plot 
Jurnal Laut Khatulistiwa, Vol. 4. No. 2 (July, 2021), Hal. 6-11.

Ip $>0 \quad$ : Penyebaran bersifat mengelompok

\section{Hasil dan Pembahasan}

\subsection{Komposisi Gastropoda}

Hasil pengamatan dan identifikasi berdasarkan ciri morfologi, ditemukan komposisi gastropoda sebanyak 7 spesies yaitu Cerithidea cingulata, C. obtuse, C. weyersi, Littoria scabra, L. undolata, Nerita violacea, dan Strombus mutabilis.

Jumlah gastropoda yang paling banyak ditemukan pada lokasi penelitian, yaitu adalah C. weyersi dan C. cingulata. Gastropoda jenis ini merupakan organisme asli yang hidup di mangrove, karena memiliki toleransi tinggi terhadap perubahan kondisi lingkungan akibat faktor fisik yang berasal dari luar sehingga organisme tersebut dapat bertahan hidup dan berkembang biak. Sedangkan jumlah gastropoda yang paling sedikit ditemukan, yaitu jenis $\mathrm{N}$. violacea karena spesies ini merupakan gastropoda pengunjung yang tidak sengaja berada dalam ekosistem mangrove (Romdhani, 2016).

\subsubsection{Gelombang}

Tinggi dan periode gelombang laut signifikan di musim barat terjadi pada tahun 2013 yaitu sebesar 0,642 meter dan 3,090 detik. Tinggi dan periode gelombang signifikan di musim peralihan I terjadi pada tahun 2012 yaitu sebesar 0,240 meter dan 1,831 detik. Tinggi dan periode maksimum gelombang laut signifikan di terjadi pada tahun 2012 yaitu sebesar 0,219 meter dan 1,818 detik. Tinggi dan periode maksimum gelombang laut signifikan di musim peralihan II terjadi pada tahun 2013 yaitu sebesar 0,383 meter dan 2,347 detik.

Pantai Batu Burung Singkawang Selatan menunjukan bahwa arah datang gelombang dominan pada musim barat, musim peralihan I dan musim timur datang dari arah timur. Sedangkan pada musim peralihan II datang dari arah barat daya. Tinggi dan periode gelombang laut signifikan tertinggi yaitu pada musim barat.

\subsection{Distribusi Gastropoda}

Pola distribusi gastropoda yang ditemukan di Desa Bakau Besar Laut bersifat mengelompok. Sifat mengelompok ini diduga disebabkan oleh beberapa faktor, yaitu kondisi lingkungan, tipe substrat dan cara bereproduksi. Sedangkan menurut Ardiyansyah (2018) menyatakan bahwa, pola sebaran mengelompok dipengaruhi oleh faktor fisika-kimia lingkungan perairan, kebiasaan makan dan kemampuan adaptasi organisme dalam suatu ekosistem.

Hasil analisis indeks morisita $N$. violacea dan $S$. mutabilis tidak dapat diperoleh. Hal ini dikarenakan analisis berhenti pada persamaan terkait signifikan bagi indeks morisita (Mu dan Mc) dan tidak dapat dilanjutkan sampai pada tahap akhir yaitu analisis standarisasi indeks morisita (Ip). Hal ini terjadi karena adanya plot dengan nilai frekuensi kenyataan sebesar nol, sehingga tidak bisa mendapatkan nilai standarisasi indeks morisita untuk mengetahui pola distribusi dari $N$. violacea dan S. mutabilis.

Tabel 1. Komposisi jenis-jenis gastropoda yang didapatkan di Desa Bakau Besar Laut

\begin{tabular}{ccllll}
\hline No & \multicolumn{1}{c}{ Kelas } & \multicolumn{1}{c}{ Ordo } & \multicolumn{1}{c}{ Famili } & \multicolumn{1}{c}{ Genus } & \multicolumn{1}{c}{ Spesies } \\
\hline 1 & Gastropoda & Sorbeoconcha & Potamididae & Cerithidea & C. cingulate \\
2 & Gastropoda & Sorbeoconcha & Potamididae & Cerithidea & C. obtuse \\
3 & Gastropoda & Cycloneritidae & Neritidae & Nerita & N. violacea \\
4 & Gastropoda & Mesogastropoda & Littorinidae & Littorina & L. scabra \\
5 & Gastropoda & Littorinimorpha & Strombidae & Strombus & S. mutabilis \\
6 & Gastropoda & Mesogastropoda & Littorinidae & Littorina & L. undolata \\
7 & Gastropoda & Caenogastropoda & Potamididae & Cerithidea & C. weyersi \\
\hline
\end{tabular}


Jurnal Laut Khatulistiwa, Vol. 4. No. 2 (July, 2021), Hal. 6-11.

Tabel 2. Jumlah jenis gastropoda yang didapatkan di Desa Bakau Besar Laut

\begin{tabular}{cccccc}
\hline No & Spesies & $\begin{array}{c}\text { Stasiun I } \\
\text { (Pemukiman) }\end{array}$ & $\begin{array}{c}\text { Stasiun II } \\
\text { (Ekowisata) }\end{array}$ & $\begin{array}{c}\text { Stasiun III } \\
\text { (Tambak) }\end{array}$ & $\begin{array}{c}\text { Jumlah } \\
\text { Individu }\end{array}$ \\
\hline 1 & C. cingulate & 38 & 40 & - & 78 \\
2 & C. obtuse & 4 & - & 17 & 21 \\
3 & N. violacea & 4 & - & - & 4 \\
4 & C. weyersi & - & 82 & 6 & 88 \\
5 & L. scabra & - & 16 & - & 16 \\
6 & S. mutabilis & - & 5 & - & 5 \\
$7 \quad$ L. undolata & - & 8 & - & 8 \\
Total per & $\mathbf{4 6}$ & $\mathbf{1 5 1}$ & $\mathbf{2 3}$ & $\mathbf{2 2 0}$ \\
stasiun & & & & \\
\hline
\end{tabular}

Tabel 3. Pola distribusi gastropoda yang didapatkan di Desa Bakau Besar Laut

\begin{tabular}{cccc}
\hline No & Jenis & Ip & Kategori \\
\hline 1. & Cerithidea cingulata & 0,537 & Mengelompok \\
2. & C. obtusa & 0,577 & Mengelompok \\
3. & Neritina violacea & - & - \\
4. & C. weyersi & 0,621 & Mengelompok \\
5. & Littoria scabra & 0,613 & Mengelompok \\
6. & Strombus mutabilis & - & - \\
7. & L. undolata & 0,672 & Mengelompok \\
\hline
\end{tabular}

\subsection{Parameter Lingkungan}

Kisaran nilai suhu yang diperoleh pada masing-masing stasiun pengamatan adalah 30 $33^{\circ} \mathrm{C}$. Menurut Romdhani (2016) kisaran suhu $25-32^{\circ} \mathrm{C}$ masih bisa ditoleransi oleh organisme perairan. Sehingga dapat dikatakan kondisi suhu pada lokasi penelitian masih tergolong layak untuk kehidupan gastropoda karena masih masuk dalam kisaran suhu yang ditentukan.

Nilai salinitas pada stasiun pengamatan adalah 20-25\%o. Salinitas di lokasi penelitian tergolong rendah karena daerah tersebut berada di dekat muara sungai. Sehingga menyebabkan salinitas rendah untuk kategori perairan laut. Menurut Manalu (2019) secara umum salinitas suatu perairan di Indonesia berkisar antara $32-34{ }^{\circ} \mathrm{C}$. Salinitas suatu perairan dipengaruhi oleh beberapa faktor seperti keadaan lingkungannya , musim, serta interaksi antara laut dan daratan.

Derajat keasaman $(\mathrm{pH})$ air sekitar plot pada lokasi pengamatan menunjukkan nilai 7,7-8,2.
Menurut Wahyuni (2014), pH ideal untuk kehidupan gastropoda adalah 6,8-8,5. Jadi dapat dikatakan bahwa nilai pH di Desa Bakau Besar Laut cukup baik untuk kelangsungan organisme gastropoda.

Jenis substrat yang diperoleh pada lokasi pengamatan yaitu pasir berlempung dan lempung berpasir. Menurut Nurliya (2017), kandungan bahan organik sedimen pada substrat berlumpur cenderung lebih tinggi dari substrat berpasir, karena pada substrat berlumpur cenderung dapat mengakumulasi bahan organic. Hal ini disebabkan oleh tekstur dan ukuran sedimen yang halus untuk memudahkan bahan organic masuk.

\section{Kesimpulan}

Komposisi gastropoda yang ditemukan terdiri dari Cerithidea cingulata, C. obtusa, C. weyersi, Nerita violacea, Littoria scabra, $L$. undolata, dan Strombus mutabilis.

C. cingulata, C. obtusa, C. weyersi, Littoria scabra, dan L. undolata mempunyai pola 
Jurnal Laut Khatulistiwa, Vol. 4. No. 2 (July, 2021), Hal. 6-11.

distribusi yang mengelompok. Sedangkan $N$. violacea dan $S$. mutabilis tidak dapat diketahui pola distribusinya karena syarat analisis indeks morisita tidak terpenuhi.

\section{Daftar Pustaka}

Ahmad. 2018. Identifikasi Filum Mollusca (Gastropoda) di Perairan Palipi Soreang Kecamatan Banggae, Kabupaten Majene. Universitas Islam Negri Alauddin, Makassar (skripsi).

Andriani, N. Andriman, dan E. Sumiasih. 2018. Pola Distribusi dan Kepadatan Keong Bakau (Telescopium telescopium) di Ekosistem Mangrove Desa Mangkapan Kecamatan Sungai Apit Kabupaten Siak Provinsi Riau, Universitas Riau.

Ardiyansyah, F. 2018. Pola Distribusi dan Komposisi Gastropoda Pada Resort Kucur TN Alas Purwo. J. Biologi dan Pembelajaran Biologi. 3 (2).

Hamida, A. G. Rahayu dan W.D. Kartika. 2016. Pola Distribusi Gastropoda di sekitar Tempat Pelelangan Ikan (TPI) Tanjung Jabung Barat. J. Biologi. 18:51-56.

Krebs, C.J. 1989. Ecological Methodology, Harper Collins Publisher, New York.

Manalu, L. Y. 2019. Kepadatan Populasi dan Pola Distribusi Gastropoda Cerithidea quonyii di Hutan Mangrove Perairan Desa Sungai Cingam Kecamatan Rupat Kabupaten Bengkalis Provinsi Riau.

Nurliya. 2017. Studi Ekologi Keong Mata Merah (Cerithidea obtusa) Pada Ekosistem Muara Sungai Jangkang, Desa Selat Baru, Kabupaten Bengkalis, Provinsi Riau.

Romdhani, A. M., Sukarsono., dan R.E. Susetyarini. 2016. Keanekaragaman Gastropoda Hutan Mangrove Desa Baban Kecamatan Gapura Kabupaten Sumenep Sebagai Sumber Belajar Biologi, J. Pendidikan Biologi Indonesia. 2:161-167.

Wahyuni, S. R. Yolanda, A.A. Purnama. 2014. Struktur Komunitas Gastropoda (Moluska) Di Perairan Bendungan Menaming Kabupaten Rokan Hulu, Riau. 